\title{
EM BUSCA DO CONHECIMENTO E DA AFIRMAÇÃO DA CIDADANIA
}

\author{
Veronika Paulics \\ Silvio Caccia Bava
}

\begin{abstract}
Resumo: Desde a sua fundação, há 15 anos, o Pólis - Instituto de Estudos, Formação e Assessoria em Políticas Sociais, tem se voltado para a pesquisa aplicada, especialmente no meio urbano, buscando fortalecer as ações da sociedade civil, local e global, na direção do aprofundamento da democracia e da melhoria da qualidade de vida.

Palavras-chave: pesquisa aplicada; urbano; não-governamental.
\end{abstract}

\begin{abstract}
Since its founding 15 years ago, Polis-the Institute for Study, Professional Preparation and Consulting in the Social Sciences-has turned its attention to applied research, particularly within the urban context, seeking to strengthen civil, local and global initiatives aimed at enhancing democracy and improving overall quality of life.

Key words: applied research; urban; non-governmental.
\end{abstract}

Pólis (do grego) S.F.: Cidade, região habitada, estado, reunião dos cidadãos, cidadania, democracia.

$\mathrm{E}$ $\mathrm{m}$ meados dos anos 80, depois de 20 anos de ditadura, o Brasil dava os primeiros passos no sentido da redemocratização de suas instituições políticas. Por meio da pressão social das manifestações de rua, dos movimentos sociais, de um laborioso trabalho de organização social - que inicialmente construiu organizações locais e posteriormente resultou na construção de fóruns, redes de entidades, centrais de representação dos trabalhadores, partidos políticos -, reconquistaramse direitos fundamentais como os da liberdade de organização partidária, liberdade de imprensa, o direito do voto para eleição dos prefeitos das capitais.

Ainda que a transição democrática tenha se caracterizado como uma transição "por cima", isto é, liderada pelos próprios setores no poder, este longo processo, que muitos consideram ainda inconcluso, teve alguns momentos marcantes como o processo de elaboração da Constituição de 1988, as Diretas Já!, as eleições municipais em importantes centros urbanos elegendo governos compro- metidos com a universalização de direitos, que expressavam a irrupção de novos atores sociais e políticos no cenário nacional.

Outro aspecto interpretado como expressão desses movimentos de afirmação da cidadania foi a eleição para o Congresso Nacional, para as Assembléias Legislativas e para as Câmaras Municipais de representantes de movimentos sociais, cuja principal característica era a afirmação de sua autonomia diante dos mecanismos tradicionais de cooptação, clientelismo, patrimonialismo, tão característicos da história política brasileira.

Ou seja, abria-se um período da história de nosso país em que novas forças sociais e políticas passaram a disputar democraticamente com as oligarquias tradicionais o controle e a gestão da máquina pública. Essas novas forças alcançaram vencer eleições que colocaram no governo de importantes cidades do país lideranças sociais que nunca haviam experimentado o desafio de governar. E, em muitos sentidos, tais novas administrações democráticas herdaram o legado do período autoritário.

Sob a égide da ditadura, o intenso processo de urbanização ocorrido nos anos 70 e 80 inscreveu duramente nas cidades a marca da segregação social. A opção pela 
dualização de nossas cidades, ao privilegiar determinados bairros, sucatear políticas públicas que tiveram muito melhor qualidade no passado como as de educação e saúde, sacrificar políticas como a produção de habitações populares impulsionando o surgimento de favelas por toda parte, criou um legado para essas novas administrações democráticas que seus recursos financeiros e de gestão não estavam capacitados para enfrentar.

Ao desafio de formular políticas públicas orientadas para atender aos interesses das maiorias, especialmente dos mais pobres, somava-se a necessidade de enfrentar o déficit social acumulado e recuperar a máquina administrativa, torná-la eficiente e moralizá-la. Mesmo nessas condições adversas, experiências inovadoras como Lages e Boa Esperança sinalizavam possibilidades de melhorias efetivas, ainda que limitadas, das condições de vida da população, a partir dos esforços de democratização da gestão municipal.

É neste contexto - e fruto também dessa nova conjuntura de mobilização das energias sociais antes represadas pela ditadura - que um grupo de cerca de 30 pessoas abre uma discussão sobre a necessidade de se criar uma espécie de think tank, ou seja, uma instituição capaz de produzir conhecimentos que apoiassem as iniciativas de democratização da gestão pública municipal e de formulação de políticas públicas inovadoras orientadas para promover a inclusão social.

A proposta que foi se desenhando era a criação de um instituto orientado para sistematizar, analisar, difundir e debater as práticas sociais inovadoras de gestão municipal e de participação popular. Originalmente esse grupo, majoritariamente vinculado ao Partido dos Trabalhadores, era constituído de professores universitários, técnicos de órgãos públicos, especialistas em educação popular. As discussões que acabaram por definir seu perfil, realizadas na sede do Sindicato dos Arquitetos, tiveram um efeito catalisador. Atraíram amigos, colegas, outras pessoas que se identificavam com a proposta e, por força da adesão de numerosos outros profissionais, o Pólis Instituto de Estudos, Formação e Assessoria em Políticas Sociais nasceu em 6 de junho de 1987, como uma sociedade civil sem fins lucrativos, autônoma, com a marca do pluralismo partidário. Seus sócios fundadores são 108 pessoas com variados perfis profissionais - arquitetos, advogados, economistas, sociólogos, pedagogos, historiadores, assistentes sociais, engenheiros, etc.

Desde o início, o seu objetivo central foi o de produzir conhecimentos e intervir no espaço público das cidades na perspectiva da democratização da sociedade e ampliação dos direitos sociais e políticos de cidadania. Os temas do urbano, das políticas públicas, das relações dos governos municipais com os movimentos sociais e entidades da sociedade civil foram, e continuam sendo, o foco que torna o Instituto Pólis uma entidade singular.

Colocavam-se como seus objetivos específicos:

- "1. Realizar estudos, análises e pesquisas que abordem as múltiplas dimensões da questão urbana e dos direitos de cidadania e que abarquem as temáticas dos movimentos sociais, dos partidos políticos, dos processos legislativos, do poder local e da administração pública, da cultura, do cotidiano e da participação popular.

- 2. Constituir um canal efetivo de divulgação, debates e socialização de informações sobre experiências e iniciativas inovadoras, seja no âmbito dos movimentos populares e entidades da sociedade civil, seja no âmbito da administração pública nos níveis local, estadual e federal, órgãos legislativos ou entidades encarregadas da elaboração de políticas sociais.

- 3. Contribuir para a formação e capacitação dos setores comprometidos com os interesses populares, em movimentos sociais organizados, em entidades encarregadas da elaboração de políticas sociais, articulando e estabelecendo interfaces com organizações não-governamentais com objetivos semelhantes.

- 4. Prestar assessoria e consultoria aos movimentos populares, entidades não-governamentais, entidades envolvidas na gestão municipal e órgãos setoriais encarregados de políticas públicas sempre que as demandas correspondam aos objetivos do Instituto Pólis" (Pólis, 1990).

Os dois primeiros anos foram marcadamente de trabalho voluntário, em que se organizavam seminários, elaboravam-se artigos, seus sócios participavam de debates públicos, realizavam-se algumas assessorias na forma de cursos para movimentos sociais.

A eleição de Luiza Erundina para prefeita de São Paulo, pelo PT, em 1989, provocou um profundo impacto no novo Instituto Pólis. Muitos dos que participaram de sua fundação por buscar um espaço para a elaboração de políticas sociais democráticas e inovadoras foram convidados a trabalhar na Prefeitura de São Paulo - vários ocuparam cargos de secretários - e encontraram ali uma outra maneira, talvez mais efetiva, de realizar suas aspirações.

Um pequeno grupo dentre os fundadores do Instituto avaliou que manter uma entidade da sociedade civil ca- 
paz de tornar-se uma referência, um centro de conhecimentos sobre as experiências de gestão municipal e políticas públicas criadas e implementadas pelas novas administrações municipais democráticas tratava-se de uma questão estratégica para a democratização do poder local e para a democratização do país. Tal avaliação confirmouse plenamente nos anos seguintes ao se constatarem as dificuldades das prefeituras democráticas em preservar a memória de suas experiências, sucessos e fracassos; e da fragilidade com que esta tarefa é assumida pelos partidos políticos.

Em 1990 o Instituto Pólis conquistou o apoio de duas agências internacionais de cooperação - uma européia, outra americana ${ }^{1}$ - que permitiram a constituição de uma equipe técnica contratada e a criação de uma pequena infraestrutura necessária para seus trabalhos. Passou a haver maior profissionalismo em suas atividades, sem dispersar nem dispensar a rede de colaboradores construída nos anos anteriores.

O principal núcleo de suas atividades era, e segue sendo, a pesquisa aplicada, que se estrutura por áreas temáticas: os movimentos populares e suas relações com o poder público, a gestão municipal democrática e seus mecanismos de participação, o acompanhamento e análise de políticas públicas como as de habitação, transportes, meio ambiente, cultura.

No início dos anos 90, nas discussões anuais de avaliação e planejamento realizadas pela equipe técnica, foram tomadas duas iniciativas que contribuíram decisivamente para qualificar a intervenção do Instituto Pólis no espaço público das cidades: priorizar sua relação com fóruns e redes de entidades da sociedade civil e criar um Centro de Documentação e Informação.

Uma avaliação realizada em 1991 reconheceu a existência de um amplo número de organizações de base no meio urbano brasileiro. Essas entidades, principalmente resultantes dos trabalhos originados pelas comunidades eclesiais de base da Igreja Católica, na época muito influenciadas pela Teologia da Libertação, mantinham-se contudo isoladas, com grande dificuldade de articulação entre si e de articular suas demandas. Tal condição provocava, por sua vez, maior dificuldade de politizar as necessidades apresentadas por essas entidades de base e de remeter a solução para a esfera da reformulação das políticas públicas.

Essa avaliação levou o Instituto Pólis a apoiar decisivamente alguns fóruns de ONGs e movimentos sociais, participando de suas coordenações nacionais. São eles o
Fórum Nacional da Reforma Urbana, o Fórum Nacional de ONGs e Movimentos Sociais em Defesa do Meio Ambiente e do Desenvolvimento, o Fórum Nacional de Participação Popular. Alguns anos depois, pelas mesmas razões, o Instituto Pólis passou a participar também da direção, ou contribuindo para sua criação, do Fórum Intermunicipal de Cultura, do Fórum Lixo e Cidadania, do Fórum Nacional de Segurança Alimentar, do Fórum Paulista de ONGs e da Associação Brasileira de Organizações Não-Governamentais.

Os resultados iniciais reforçaram a convicção dessa opção estratégica. Já em 1991, discutindo qual deveria ser sua intervenção na Conferência das Nações Unidas em Defesa do Meio Ambiente e do Desenvolvimento - a Rio 92 -, o Instituto Pólis dispôs-se a introduzir a questão urbana na conferência, tema que não havia sido previsto. Para atingir tal objetivo o instituto propôs à coordenação do Fórum Global a criação de uma conferência específica sobre as cidades e, ao coordenar suas atividades, coordenou também a elaboração do Tratado "Por cidades justas, democráticas e sustentáveis", que se constituiu uma referência mundial na discussão da sustentabilidade das cidades. Ciente de que numa intervenção dessa ordem requeria a sistematização de um amplo debate em torno do tema, o Instituto Pólis realizou previamente uma pesquisa e produziu uma publicação pioneira intitulada Meio ambiente urbano, amplamente distribuída nesse evento internacional.

Essas práticas de associar a pesquisa e a socialização do conhecimento nos fóruns de que participa foi um aprendizado que até hoje orienta as atividades do Instituto Pólis. Assim, a publicação trimestral Pólis, que hoje está em seu $40^{\circ}$ número, divulgou vários estudos realizados pelo instituto sobre as políticas municipais de cultura, políticas municipais de segurança alimentar, manejo dos resíduos sólidos, participação popular, reforma urbana, entre outros.

A outra iniciativa decisiva para posicionar o instituto como um centro de produção de conhecimentos foi ele ter criado o Centro de Documentação e Informação - CDI, assumindo custos relativamente elevados para seu orçamento, uma área que inicialmente se desenhou como de apoio à pesquisa interna, mas que pelo crescimento constante de seu acervo de documentos, papers, pesquisas, dados estatísticos organizados em bancos de dados, hoje tem suas atribuições ampliadas, encontra-se aberto para consultas públicas e é recomendado pelas melhores universidades brasileiras a seus estudantes de mestrado e doutorado.

Já na primeira metade dos anos 90, o Instituto Pólis começou a se destacar não só pela qualidade dos seus tra- 
balhos de pesquisa, apoiados por um número crescente de instituições nacionais (CNPq, Finep, Fapesp) e internacionais (Novib, Fundação Ford, Oxfam, CCFD, Christian Aid, Frères des Hommes), mas por sua especialização temática, reiterando sua decisão estratégica de manter o foco das atividades nos temas urbanos, evitando a tentação de ampliar seus temas em razão de oportunidades que se apresentavam. Desde seu início até os dias de hoje, seu objeto de trabalho concentra-se no plano das relações entre as representações da cidadania e os governos locais, nas políticas públicas e nos processos de participação popular, na análise da gestão municipal.

Outra dimensão dos trabalhos que permitiu o acúmulo de uma expertise nos temas urbanos foi a crescente integração do instituto com projetos de pesquisa internacionais e redes internacionais de produção de conhecimentos nessas áreas. Tais relações rompem um certo provincianismo do Instituto Pólis e o integram a vários importantes circuitos que trabalham seus temas. É o caso, por exemplo, dos trabalhos realizados com o International Development Research Council, do Canadá; com o Lincoln Institute, com o United Nations Research Institute for Social Development, organismo das Nações Unidas; ou da participação em redes como o Global Urban Research Initiatives, o Management on Social Transformations, redes estas articuladas com o Centre for Urban and Community Studies da Universidade de Toronto. Em 1998 o Instituto Pólis é convidado a participar da assembléia de fundação e a integrar uma articulação global: o Forum of Researchers on Human Settlements.

De fato, o processo de integração com iniciativas internacionais - facilitado em muito pelo ciclo dos anos 90 das Conferências das Nações Unidas - torna cada vez mais comum o convite a seus técnicos para participarem de eventos internacionais. O que, aliás, levanta um problema de prioridades e requer novas definições da parte de seu coletivo de técnicos. Se a ênfase do trabalho do instituto é apoiar os agentes de transformação social que operam a democratização do poder local, a participação nos eventos internacionais deve se orientar para potencializar estas práticas, buscando evitar a pulverização de esforços.

Tais critérios aproximaram o Instituto Pólis também de redes internacionais de ONGs, em que a troca de conhecimentos e a articulação de iniciativas conjuntas se fazem nesta perspectiva de potencializar os trabalhos locais. É o caso do Habitat International Coalition, da Asociación Latinoamericana de Organizaciones de Promoción, do Conselho de Educação de Adultos da América Latina, da
Aliança para um Mundo Responsável e Solidário, da Rede de Direito Alternativo, redes às quais o instituto torna-se associado.

Além disso, abrem-se oportunidades para a especialização de seus técnicos em universidades e centros de pesquisa de outros países, como na Inglaterra, no Institute for Development Studies da Universidade de Sussex; como no Institute of Latin American Studies da Universidade do Texas - Austin.

A participação do Instituto Pólis na Conferência Habitat II, em Istambul, em 1996, bem como de seus eventos preparatórios no Brasil, pode ser encarada como um momento de afirmação de maior maturidade na produção das suas pesquisas, assim como na formulação de proposições no campo das políticas públicas.

Já na segunda metade dos anos 90 , a criação por parte do instituto do boletim quinzenal Dicas - idéias para a ação municipal, apoiado pela Fundação Friedrich Ebert, surge como uma iniciativa pioneira na sistematização e difusão de experiências inovadoras em gestão local. Esse boletim ganhará ampla difusão nos anos recentes, com o apoio do BNDES, que patrocina, por exemplo, a produção de uma publicação Pólis denominada 125 Dicas Idéias para a ação municipal, com uma tiragem especial de 25 mil exemplares, distribuída a todos os prefeitos do país. O Dicas continua a ser publicado regularmente e ganha recentemente também uma edição eletrônica na página web do instituto (www.polis.org.br).

Com o surgimento de vários prêmios para experiências inovadoras de gestão municipal o instituto é convidado a integrar os comitês técnicos, por exemplo, do Programa Gestão Pública e Cidadania, da Fundação Getúlio Vargas, e do Projeto Prefeito Criança, da Fundação Abrinq.

Nesse período, torna-se mais intensa a troca de conhecimentos e a participação em atividades articuladas com o meio acadêmico. São realizadas iniciativas conjuntas de pesquisa com o Cenedic (Centro de Estudos dos Direitos da Cidadania), do Departamento de Sociologia da Universidade de São Paulo e com o Instituto de Estudos Especiais da Pontifícia Universidade Católica de São Paulo.

A proliferação de políticas públicas municipais voltadas para o combate à pobreza e para a promoção do desenvolvimento local - políticas como bolsa-escola, renda mínima, microcrédito - levam o instituto a desenvolver uma nova linha de pesquisa, pioneira quanto ao impacto social dessas políticas e às potencialidades dos governos municipais atuarem sobre o desenvolvimento local. Essa linha de pesquisa se orienta para a avaliação de políticas 
públicas e a produção de indicadores de impacto social dessas políticas, projetos realizados com o apoio do Unicef, da Unesco e de outros organismos vinculados ao sistema das Nações Unidas. Seus resultados estão divulgados nas publicações Desenvolvimento local, Renda mínima e Como reconhecer um bom governo. Tal linha de trabalho levou também o Instituto Pólis a participar de projetos como a produção de Mapas de Exclusão Social de vários municípios.

As mudanças nas políticas de cooperação internacional, no sentido de orientar seus financiamentos para projetos de impacto social, reduzindo seus orçamentos para pesquisa, apresentaram novos desafios para a produção de conhecimentos e para o Instituto Pólis, que decidiu abrir uma frente de trabalhos de consultoria nos quais a formulação de políticas passou a ser orientada pelas necessidades de governos municipais.

As inflexões nas políticas de cooperação e a crise de financiamento dos trabalhos do instituto levaram a uma decisão de seus técnicos em promover uma avaliação institucional para reafirmar sua missão e seus objetivos de reforçar as capacidades dos agentes sociais de mudança que operam no plano local. Essa avaliação apontou uma dispersão das atividades do instituto no plano nacional, pautadas muito mais pelas demandas que por seu plano de atividades. A avaliação apontou também uma fragilização nas relações com os movimentos sociais e com as entidades da sociedade civil. Fruto de tal avaliação, o instituto reelaborou seu planejamento e concentrou suas atividades principalmente na região da Grande São Paulo e, posteriormente, no município de São Paulo, tendo como objetivo construir relações estáveis e duradouras com os mais importantes movimentos sociais presentes na cidade. O foco é o fortalecimento das capacidades das representações coletivas que atuam na defesa e ampliação dos direitos de cidadania.

Em seu atual plano quadrienal, o Instituto Pólis reafirma a cidade e a atuação no campo das políticas públicas e do desenvolvimento local como os elementos que definem sua identidade: "a cidadania, como conquista democrática, é o eixo articulador de nossa intervenção dirigida à construção de cidades justas, democráticas e sustentáveis".

Nos termos do Plano Quadrienal 2001-2004 (Pólis, 2001), o instituto identifica novos desafios, "que deverão ser enfrentados se quisermos manter uma perspectiva dinâmica e de contínuo aperfeiçoamento e desenvolvimento de nossa ação".
As prioridades colocadas no plano são:

- Fortalecer os vínculos do Pólis com movimentos sociais e entidades da sociedade civil, colocando à sua disposição nossa capacidade técnica em atividades de formação, assessoria e disseminação.

- Atuar prioritariamente na metrópole de São Paulo, o que significa desenvolver competências para posicionar-se perante a complexidade dos problemas de uma metrópole de 17 milhões de habitantes e 39 municípios e respectivos governos locais. Dentro dessa focalização, o município de São Paulo, com 10 milhões de habitantes, deve ter prioridade. No entanto, o instituto continuará destinando um olhar especial para a região do $\mathrm{ABC}$, dando continuidade às intervenções já iniciadas.

- Produzir e aplicar metodologias de acompanhamento e avaliação de governo e de políticas específicas destinadas a ampliar a capacidade de controle público sobre a ação do governo municipal de São Paulo e, com isso, potencializar a ação fiscalizadora e propositiva dos movimentos e entidades. Com essa iniciativa, o instituto quer realizar uma experiência que possa ser reproduzida em outras localidades.

- Aprofundar o sentido propositivo de nossa intervenção e orientá-lo para apoiar a sociedade e governos locais democráticos em projetos de formulação, disseminação, implantação e avaliação de políticas públicas locais voltadas à remoção de entraves e promoção do desenvolvimento com inclusão social.

- Avançar conceitualmente e metodologicamente no domínio da problemática do desenvolvimento econômico local, compreendendo e dando visibilidade a soluções para a sua articulação com o desenvolvimento local pensado de maneira ampla.

- Estabelecer parcerias duradouras em que se reforcem os vínculos entre os parceiros e a potencialidade de trabalhos conjuntos, o que leva o instituto a continuar investindo na articulação com outras entidades e na criação de novos espaços de intervenção.

- Consolidar a visão do Pólis como um centro de excelência em pesquisa aplicada no campo das políticas públicas urbanas e da gestão municipal.

- Consolidar e aprofundar o processo de incorporação, nas intervenções do Pólis, da perspectiva de gênero e dos Direitos Humanos, principalmente na esfera dos novos direitos - econômicos, sociais, culturais e ambientais. 
- Ampliar a presença do Pólis na Internet, transformando a página (www.polis.org.br) em uma referência nacional no campo das políticas públicas no ambiente urbano e da relação da sociedade civil com governos locais.

- Ampliar e diversificar as fontes de recursos para o financiamento das atividades do Pólis, através da busca de novas formas de parceria e da venda de serviços em áreas onde o instituto tem acúmulo de conhecimentos e experiência de atuação.

- Orientar o processo de desenvolvimento institucional do Pólis para o enfoque no aperfeiçoamento das suas práticas de acompanhamento e avaliação de ações, sem deixar de lado a constante busca de instrumentos de gestão mais participativos e democráticos.

- Evitar a dispersão de atividades da equipe do instituto no atendimento a demandas, promoção de iniciativas ou incorporação de novas temáticas sem aderência às diretrizes do presente plano.

- Ampliar a articulação interna da equipe, realizando ações integradas.

Uma inovação adotada nesse plano é uma organização matricial por Projetos Estruturantes, que articulem as áreas de pesquisa e intervenção e abarquem um conjunto amplo de ações do Instituto Pólis, o qual pretende responder ao desafio de evitar a dispersão de atividades da equipe no atendimento a demandas ou a incorporação de novas temáticas e iniciativas sem aderência às diretrizes do presente plano, buscando potencializar o alcance de nossas intervenções. Nesse sentido, o instituto busca articular o acúmulo nas áreas de participação popular, cultura, meio ambiente urbano, segurança alimentar, desenvolvimento urbano, avaliação de políticas públicas e construção de indicadores sociais, com a construção de novas capacidades nas áreas de pesquisa, formação e assessoria em políticas sociais.

O rol dos projetos estruturantes, por si só, já diz bastante da estratégia que o Pólis adotou e das prioridades que elegeu para o período 2001-2004:

- Labororatório de Desenvolvimento Local e Inclusão Social: formulação e apoio à implantação de propostas de remoção de entraves e promoção do desenvolvimento local com inclusão social.
- Observatório dos Direitos do Cidadão de São Paulo: construção e aplicação de metodologia de acompanhamento e avaliação sistemáticos das políticas públicas no município de São Paulo.

- Escola de Cidadania e Políticas Públicas para Lideranças Sociais: através de processos de capacitação contribuir para o fortalecimento da capacidade de intervenção dos movimentos sociais e entidades da sociedade civil no campo das políticas públicas urbanas.

- Disseminação de Proposições e Informações em Políticas Públicas Locais: disponibilização, à sociedade e aos governos locais democráticos, de informações e propostas em políticas públicas locais.

Tais diretrizes de trabalho são um desafio que encontra seus limites nas enormes dificuldades de financiamento que hoje se colocam para o conjunto das ONGs e particularmente para o Instituto Pólis. Mais do que nunca são necessários o reconhecimento do caráter de utilidade pública e a criação de mecanismos de financiamento público para as ONGs, sem os quais a autonomia destas entidades, sua capacidade de produção de conhecimentos e seus objetivos de fortalecimento das lideranças sociais e da sociedade civil organizada tornam-se cada vez mais difíceis de ser alcançados.

\section{NOTA}

1. Trata-se da EZE, hoje EED, entidade alemã que continua apoiando as atividades do Pólis, e a IAF - InterAmerican Foundation que, por mudanças de estratégia, deixa de apoiar o Pólis em 1996.

\section{REFERÊNCIAS BIBLIOGRÁFICAS}

PÓLIS. Relatório de atividades 1987-1990. São Paulo, 1990. . Plano quadrienal 2001-2004. São Paulo, 2001.

Veronika Paulics: Diretora do Instituto Pólis (veronika@polis.org.br). Silvio Caccia Bava: Diretor do Instituto Pólis (scbava@polis.org.br) 